\title{
The Behaviour for SRC Willow Inger in Experimental Trial Ghilad, Romania
}

\author{
Cornelia HERNEA ${ }^{1}$, Willhelm HOLLERBACH${ }^{2}$, Danut TRAVA², Mihaela CORNEANU ${ }^{*}$ \\ ${ }^{1}$ Faculty of Horticulture and Forestry, Banat's University of Agricultural Sciences and Veterinary \\ Medicine "King Michael I of Romania" from Timișoara, 119 Calea Aradului, 30645 Timișoara, Romania \\ ${ }^{2}$ SC Rebina Agrar SRL, Ghilad, Timiș County, Romania \\ *)Corresponding author, e-mail: micorneanu@yahoo.com
}

BulletinUASVM Horticulture 72(2) / 2015

Print ISSN 1843-5254, Electronic ISSN 1843-5394

DOI:10.15835/buasvmcn-hort:11657

\begin{abstract}
The use of bioenergy are increasing in many European countries and an important role will be played by biomass produced in willow SRC. Short Rotation Coppice (SRC) willow was developed in Sweden in 1970 and it is cultivated for the production of wood chips. In Romania there are not more than 800 hectares, half of them are in Banat area. In this context assessing the biomass yield in the different experimental trial are very important. Research have been made in three SRC willow experimental trials established in Ghilad, Timis County, Romania. The material consist in willow Inger. All three trails have been established in the year 2011 but harvested in different years. Measurements and observation were made on 15 plants at the end of the 2014 season. One plant from each experimental trial has been harvested and then weight in order to establish their aboveground and underground biomass. Research highlight significant differences according with a number of shoots per stump and shoot diameter according with harvested year. According with stump age and the number of harvests, significant differences were established for quantitative character diameter. There also have been put in evidence the differences between the aboveground and underground biomass for different willow age. This screening about biometric characteristic and aboveground biomass showed high value for willow SRC harvested every year. We have to notice that any economic aspect have not been evaluated
\end{abstract}

Keywords: biomass, biometric observation, SRC, willow.

\section{INTRODUCTION}

According to Argus (1977), there are around 450 shrubs and tree species from genus Salix found mainly in Northern Hemisphere. Most of the willows are well adapted to hipoxonic conditions that mean that mineral nutrition are preferred to the organic one. This is the reason why many of the willows can growth well on soil rich on minerals and/or radionuclides. These species are also used for soil phytoremediation (Corneanu et $a l ., 2010$ ) and like pioneer species by their role in ecosystem restoration. Willows have the ability to developed on abandoned farmland, sandy dunes, gravel, coastal sandy soil (Kuzovkina and Quigley, 2005; Corneanu et al., 2011). They developed an ectomycorrhizae association that use phosphorus and endomycorrhizae association that use organic nitrogen (Schramm, 1966; Lodge, 1989; Heijden and Kuyper, 2003).

Salix species represent a very important source in order to combat environmental degradation (Mamashita et al., 2015). Nearly twothirds of degradation types can be remedied by Salix species: soil erosion, mine spoil, industrial waste, petroleum spoil, sewage sludge, landfills etc. (Logan, 1992). There also have an important pharmaceutic role and can be used for their biomass. Biomass production used for heat and power generation can be obtained in short rotation coppice. 
There a lot of advantages of willow cultivation: fast-growing perennial plant, remarkable capacity of vegetative regeneration, very high sprouting capacity, high productivity, short rotation cycle, broad genetic base which allow an easy breeding, low economic investments after its establishment (Mola Yudegao, 2014; Pacaldo et al., 2013)

Except the production of heat and power energy, there is also others utilization of Salix: production of methanol, production of salicylic acid (in pharmaceutical industry), wood and wood products, cellulose and paper. These cultures have positive influence on conservation and protection of ecosystems, their restoration, recycling nutrients and soil conservation, through protection against wind and hydraulic erosion and positive effects on flora and fauna, which in majority of cases enrich themselves. Willow plantations are important by increasing biodiversity and decreasing the use of pesticides in intensively managed farmland landscapes (Berg, 2002).

In Sweden, starting 1980, not only willows have been cultivated for biomass but also Populus sp. Beside the capacity to produce a large amount of woody biomass, willow culture are also the ability to accumulate nutrients and pollutants from wastewater and sludge sewage, (Perttu, 1993; Perttu and Kowalik, 1997; Aronsson, 2000; Aronsson and Perttu, 2001) and radionuclides from contaminated soil (Sennerby-Forsse et al., 1993) so willow short rotation coppice act like a filter vegetation.

Research have shown that Salix viminalis and $S$. dasyclados cultivated in Sweden produce every year up to 35 tons per hectare (Greger and Landberg, 1999). Nevertheless, not only Sweden are the country where willow are cultivated for biomass. In Canada, for example, $S$. viminalis produce 10 to 12 odt ha ${ }^{-1} \mathrm{yr}^{-1}$ (Labrecque and Teodorescu, 2005).

There are many national programs in Europe (Sweden, Great Britain, Denmark, and Finland) and Canada to increase the biomass yield, to select the most productive and resistant to pests and diseases.

In the last two decades 16,000 ha of willow cultures were planted in Sweden (Wright L, 2006, Dimitriou et al. 2011, Mola Yudego and Aronsson, 2008, Mola Yudego, 2011) while in Romania since 2005,800 ha of were planted, half of them being in Banat area.
The aim of this work, is to make a screening about biometric characteristic, diameter and number of shoots for SRC willow Inger and to put in evidence the differences between the aboveground and underground biomass for different willow age.

\section{MATERIALS AND METHODS}

Research have been made in three SRC willow experimental trials established in Ghilad, Timis

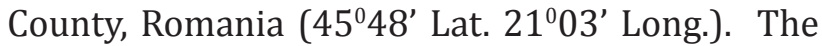
material consist in willow INGER. All three trails have been established in the year 2011. The aboveground biomass was harvested in different years, annual in first trial (winter 2011/2012, $2012 / 2013$ and $2013 / 2014$ ), for two times in winter 2011/2012 and 2012/2013 in the second trial and only in 2011/2012 winter, in the third ones. Measurements were made on 15 plants at the end of the 2014 season. The diameter at $1 \mathrm{~m}$ from root collar was measured with an electronic caliper (precision $0,01 \mathrm{~cm}$ ) and the number of shoots/plant were counted.

One plant from each experimental trial has been harvested at the end of the growing season and then weight in the field in order to establish their aboveground and underground biomass. The dry matter content was determined for all 75 shoots by drying material at $105^{\circ} \mathrm{C}$, until constant weight. To assess biomass production, an allometric relationship between $\mathrm{W}$ and stem diameter was used.

\section{$W=b D^{c}$}

Where W- biomass; D - diameter measured at $1 \mathrm{~m}$ from root collar; b, c - parameters.

A biometric observation like diameter $(\mathrm{mm})$ and length $(\mathrm{cm})$ were also performed. Statistical analyzes have been done by STATISTICA 10 software.

\section{RESULTS AND DISCUSSION}

Variability of diameter measured at $1 \mathrm{~m}$ from root collar and number of shoots per stump, characters relevant for biomass production are presented in table 1.

The sprouting capacity of willow increases after multiple harvests. An average of 16.0 shoots per stump was recorded after tree harvests and only 4.07 shoots per stump after one harvest. There is a high variability for this character (Tab.1). Significant differences have been recorded for trial 
S1 (three harvests) and the others trials, S2 (two harvests) and S3 (one harvest) but no significant differences between trial S2 and S3. Shoots diameters are inversely proportional with the number of shoots per stool, a negative correlation $(r=-0,4402)$ that we expected according with dates registered in table 1 . A significant inverse relationship between average shoots diameter and total numbers of shoots was also observed by Mosseler (2014). The stump age is very important for quantitative characters because root system of willow plants are essential for their survival, sprouting, growth and finally biomass accumulation.

A comparative analysis about shoots grew on a one-year stump and four years stump highlight that one year shoots length range from 100 to $350 \mathrm{~cm}$ for one-year stump and 100 to $450 \mathrm{~cm}$ for 4 years stump. There are significant positive differences between plants (Tab. 2).

Average length of three years shoots/ four years stump (436.4cm) and two years shoots/ four years stump $(407.3 \mathrm{~cm})$ are significantly higher than one-year shoot/four years stump $(277.0 \mathrm{~cm})$. There are not significant differences between two years shoots length and three years shoots length but there are significant differences between diameters, $38.5 \mathrm{~cm}$ for three years shoots and almost half of this value, $21.4 \mathrm{~cm}$ for two years shoots. There were recorded significant differences between these two, three and one year shoots for length shoots but not for diameter shoots. Like we expected, significant positive correlation were recorded for all trials (Tab.3). A similar relation, between average shoots length and average shoots diameter was observed by Mosseler (2014).

Biomass yield is the aim of short rotation coppice willow so, fresh and dry biomass for the plants harvested were determined (Tab. 4)

The plants were randomly selected so the lower weight for plant harvested by experimental trail S3 can be explained.

In order to establish the yield ( $\mathrm{t} \mathrm{ha} \mathrm{y}^{-1}$ year $\left.^{-1}\right)$ allometric equation were assessed (Tab. 5).

Tab. 1. The biometric characteristics of willow INGER (mean \pm S.E) in three experimental trial with different last harvesting date, winter 2011/2012 for S1, winter 2012/2013 for S2, winter 2013/2014 for S3

\begin{tabular}{cccccccc}
\hline Experimental trial & \multicolumn{3}{c}{ Diameter $(\mathrm{mm})$} & \multicolumn{3}{c}{ Shoots no. } \\
\hline $\mathrm{S} 1$ & 8.50425 & +0.247499 & $\mathrm{c}$ & 16.00000 & +2.007130 & $\mathrm{a}$ \\
\hline $\mathrm{S} 2$ & 13.90893 & +0.657777 & $\mathrm{~b}$ & 6.86667 & +0.515167 & $\mathrm{~b}$ \\
\hline S3 & 24.08984 & +1.243279 & $\mathrm{a}$ & 4.06667 & +0.520683 & $\mathrm{~b}$ \\
\hline Note: Different letters between cultivars denote significant differences (Duncan test, $\mathrm{p}<0.05)$.
\end{tabular}

Tab. 2. The biometric characteristics (mean \pm S.E) of four plants harvested at different age

\begin{tabular}{ccccccccc}
\hline Stump (years root_years shoots) & \multicolumn{3}{c}{ Diameter $(\mathrm{mm})$} & \multicolumn{3}{c}{ Length cm) } \\
\hline $4 \_3$ & 38.53429 & +7.537593 & a & 436.4286 & + & 68.18597 & a \\
\hline $4 \_2$ & 21.44077 & + & 1.963662 & b & 407.2692 & + & 29.39328 & a \\
\hline $4 \_1$ & 15.47149 & + & 0.781253 & bc & 277.0000 & + & 12.02207 & b \\
\hline 1_1 & 13.09000 & + & 2.480822 & c & 202.4000 & + & 35.06080 & b \\
\hline Note: Different letters between plants denote significant differences (Duncan test, $\mathrm{p}<0.05)$.
\end{tabular}

Tab. 3. Correlation between diameter $(\mathrm{mm})$ and length $(\mathrm{cm})$ for willow INGER of plants with different age of roots and shoots

\begin{tabular}{ccccc}
\hline \multirow{2}{*}{ Character } & \multicolumn{4}{c}{ Stool (years root_years shoots) } \\
\cline { 2 - 5 } & $4 \_3$ & $4 \_2$ & $4 \_1$ & $1 \_1$ \\
\hline Diameter $(\mathrm{mm})-$ Length $(\mathrm{cm})$ & 0.945092 & 0.970523 & 0.915285 & 0.975257 \\
\hline Note: Marked correlations are significant at & $\mathbf{0} 0.05)$. & & &
\end{tabular}


Tab. 4. Fresh, dry and oven-dry biomass (kg/plant) for three willow plants in three experimental trial with different last harvesting date, winter 2011/2012 for S3, winter 2012/2013 for S2, winter 2013/2014 for S1

\begin{tabular}{cccc}
\hline Plant harvested from & \multicolumn{3}{c}{ Aboveground biomass } \\
\cline { 2 - 4 } experimental trial & fresh & dry & oven dry \\
\hline S1 & 10.45 & 7.33 & 5.78 \\
\hline S2 & 15.50 & 12.40 & 10.14 \\
\hline S3 & 7.25 & 6.13 & 5.06 \\
\hline
\end{tabular}

Tab. 5. Parameter estimate and determination coefficient assessed on three willow INGER harvested at different ages

\begin{tabular}{|c|c|c|c|c|c|c|}
\hline \multirow{2}{*}{$\begin{array}{c}\text { Experimental } \\
\text { trial } \\
\end{array}$} & \multirow{2}{*}{$\begin{array}{l}\text { Number } \\
\text { of shoot }\end{array}$} & \multirow{2}{*}{$\begin{array}{l}\text { Diameter range } \\
(\mathrm{mm})\end{array}$} & \multirow[t]{2}{*}{ Biomass } & \multicolumn{2}{|c|}{ Estimated parameter } & \multirow{2}{*}{$\mathrm{R}^{2}$} \\
\hline & & & & $\mathrm{b}$ & $\mathrm{C}$ & \\
\hline \multirow{2}{*}{$\mathrm{S} 1$} & \multirow{2}{*}{50} & \multirow{2}{*}{$03-21$} & fresh & 0.4415 & 2.3124 & 0.9712 \\
\hline & & & oven dry & 0.3933 & 2.2848 & 0.9724 \\
\hline \multirow{2}{*}{$\mathrm{S} 2$} & \multirow{2}{*}{25} & \multirow{2}{*}{$06-32$} & fresh & 0.3876 & 2.4246 & 0.9778 \\
\hline & & & oven dry & 0.2989 & 2.4428 & 0.9836 \\
\hline \multirow{2}{*}{ S3 } & \multirow{2}{*}{5} & \multirow{2}{*}{$15-39$} & fresh & 2.4534 & 1.9219 & 0.8143 \\
\hline & & & oven dry & 2.4092 & 1.8576 & 0.7956 \\
\hline
\end{tabular}

Experimental trial S1 and S2 showed a good fit for both fresh and oven-dry biomass. A lower value for $\mathrm{R}^{2}$ were calculated for experimental trial S3 probably because a much lower number of shoots per stump. This is the reason why we will discuss biomass only for first and the second trials. According with these allometric equations, yield (t ha-1 year-1) were assessed: to $22 \mathrm{DM}$ ton ha ${ }^{-1}$ for one year shoots (experimental trial S1) and 37 DM ton ha $^{-1}$ for two year shoots (experimental trial S2). Allometric equations relating shoots weight to shoots diameter were shown before by Telenius (1995). We have to notice a very dry growing season in 2012 (289.4 mm from April to October, Gad-Romania), less than $40 \mathrm{~mm}\left(\mathrm{~m}^{2}\right)^{-1} \mathrm{month}^{-1}$ but also a very wet season in 2014 when $158.6 \mathrm{~mm}$ was recorded only in July. This severe drought and wet certainly had implications on willow growth.

\section{CONCLUSION}

Variability of willow quantitative characters, diameter and number of shoots, according with harvested year were highlighted.

Insignificant statistic differences were reported for the number of shoots per stump in experimental trial harvested after two or three years, but significant differences were reported for experimental trial harvested every year.

A negative correlation were determined between shoots diameter and the number of shoots per stump $(r=-0,4402 ; p=0,000)$.

According with stump age and the number of harvests, significant differences were established for quantitative character diameter. Both experimental trial, harvested at two and three years shown significant differences for experimental trail harvested every year, independent of age stump.

The non-linear regression for two experimental trials, one year and two years shoots, showed very good fit $\left(r^{2}>0,97\right)$.

Acknowledgments. This paper was financially supported by MEN UEFISCDI, Programme PN II 2014- 2016, project no. 111 SAROSWE.

\section{REFERENCES}

1. Argus GW (1997). Infrageneric classification of Salix (Salicaceae) in the New World. Syst. Bot. Monogr. 52:1121.

2. Aronsson P (2000). Nitrogen retention in vegetation filters in short-rotation coppice. Acta Univ. Agric. Sueciae, Silvestria, 161. 
3. Aronsson P, Perttu K (2001). Willow vegetation filters for wastewater treatment and soil remediation combined with biomass production. Forestry Chron. 77 (2):293299.

4. Berg A (2002). Breeding birds in short-rotation coppices on farmland in central Sweden - the importance of Salix height and adjacent habitat. Agriculture, Ecosyst. Environ. 90:265-276.

5. Corneanu G, Corneanu M, Netoiu C, Crăciun C, Gămăneci Gh, Lăcătuşu AR, Marinică I (eds.) (2011) - Jiu middle basin. Environmental and social implications of the extractive and energy. Monographic study. . Edit. Universitaria Craiova, 350 pp. (in Romanian)

6. Corneanu M, Răduțoiu D, Corneanu CG, Cojocaru L, Gămăneci G (2010). Waste dump consolidation and the landscape's natural and artificial rehabilitation in the middle Jiu valley (Romania). In: International Workshop "Global and Regional Environmental Protection" (Eds. I. Ionel, A. Ionescu, G. Trif Tordai, I. Vetres), vol 1: 34-37. Edit. Politehnica Timisoara.

7. Dimitriou I, Rosenqvist H, Berndes G (2011). Slow expansion and low yields of willow short rotation coppice in Sweden; implications for future strategies. Biomass Bioenerg. 35:4613-4618.

8. Greger M, Landberg $T$ (1999). Use of willow in phytoextraction. Int. J. Phytoremed. 1(2):115-123.

9. Kuzovkina YA, Quigley MF (2005). Willows beyond wetlands: uses of Salix L. species for environment projects. Water, Air, and Soil Pollution. 162:183-204.

10. Labrecque M, Teodorescu TL (2005). Field performance and biomass production of 12 willow and poplar clones in short-rotation coppice in southern Quebec, Canada. Biomass Bioenerg. 29:1-9.

11. Lodge, DJ (1989). The influence of soil moisture and flooding on formation of VA-endo and ectomycorrhizae in Populus and Salix. Plant Soil 117:243-253.

12. Logan TJ (1992). Reclamation of chemically degraded soils. Adv. Soil Sci. 17:13-35

13. Mamashita T, Larocque GR, DesRochers A, Beaulieu J, Thomas BR, Mosseler A, Major J, Sidders D (2015). Shortterm growth and morphological responses to nitrogen availability and plant density in hybrid poplars and willows. Biomass Bioenergy 81:88-97.
14. Mola-Yudego B, Aronsson P (2008). Yield models for commercial willow biomass plantation in Sweden. Biomass Bioenerg. 32(9):829-837.

15. Mola-Yudego B (2011). Trends and productivity improvements from commercial willow plantations in Sweden during the period 1986-2000. Biomass bioenergy. 35:446-453.

16. Mola-Yudego B, Dimitriou I, Gonzalez-Garcia S, Gritten D, Aronsson P (2014). A conceptual framework for the introduction of energy crops, Renewable Energy 72:2938.

17. Mosseler A, Major JE, Labrecque M, Laroque GR (2014). Allometric relationship in coppice biomass production for two North American willow (Salix spp.) across three different sites. Forest Ecologie and Management 320:190193.

18. Pacaldo RS, Volk TA, Briggs RD (2013). No significant differences in soil organic carbon contents along a chronosequence of shrub willow biomass crop fields. Biomass Bioenergy $58: 136-142$.

19. Perttu KL, Kowalik PJ (1997). Salix vegetation filters for purification of water and soils. Biomass Bioenerg. 12 (1):9-19.

20. Perttu K (1993). Biomass production and nutrient removal from municipal wastes using willow vegetation filters. J. Sustainable Forestry (3):57-70.

21. Schramm JR (1966). Plant colonization studies on black wastes from anthracite mining in Pennsylvania, Trans. Amer. Phil. Soc. N. S. 56:6-194.

22. Sennerby-Forsse L, Melin J, Rosen K, Siren G (1993). Uptake and distribution of radiocesium in fast-growing Salix viminalis L. J. Sustainable Forestry 1(3):93-103.

23. Telenius B, Verwjist T (1995). The influence of allometric variation, vertical biomass distribution and sampling procedure on biomass estimates in commercial shortrotation forest. Bioresource Technology 51:247-253

24. Van der Heijden EW, Kuyper TW (2003). Ecological strategies of ectomycorrhizal fungi of Salix repens: Root manipulation versus root replacement. Oikos 103, 668680.

25. Wright L (2006). Worldwide commercial development of bioenergy with a focus on energy crop-based projects. Biomass Bioenerg. 30:706-14. 